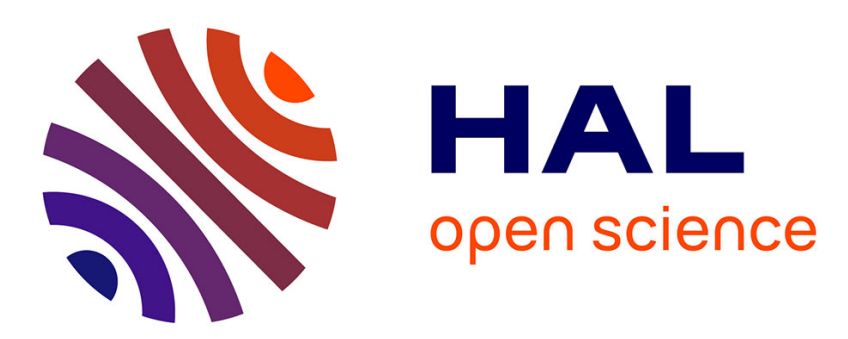

\title{
Magnitude and variability of process rates in fungal diversity-litter decomposition relationships
}

\author{
Christian K. Dang, Eric Chauvet, Mark O. Gessner
}

\section{To cite this version:}

Christian K. Dang, Eric Chauvet, Mark O. Gessner. Magnitude and variability of process rates in fungal diversity-litter decomposition relationships. Ecology Letters, 2005, 8 (11), pp.1129-1137. 10.1111/j.1461-0248.2005.00815.x . hal-01335885

\section{HAL Id: hal-01335885 \\ https://hal.science/hal-01335885}

Submitted on 22 Jun 2016

HAL is a multi-disciplinary open access archive for the deposit and dissemination of scientific research documents, whether they are published or not. The documents may come from teaching and research institutions in France or abroad, or from public or private research centers.
L'archive ouverte pluridisciplinaire HAL, est destinée au dépôt et à la diffusion de documents scientifiques de niveau recherche, publiés ou non, émanant des établissements d'enseignement et de recherche français ou étrangers, des laboratoires publics ou privés. 


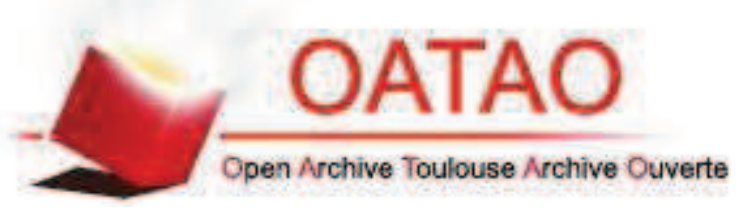

\section{Open Archive TOULOUSE Archive Ouverte (OATAO)}

OATAO is an open access repository that collects the work of Toulouse researchers and makes it freely available over the web where possible.

This is an author-deposited version published in : http://oatao.univ-toulouse.fr/ Eprints ID : 9678

To link to this article : DOI : 10.1111/j.1461-0248.2005.00815.x URL : http://dx.doi.org/10.1111/j.1461-0248.2005.00815.x

To cite this version : Dang, Christian K. and Chauvet, Eric and Gessner, Mark O. Magnitude and variability of process rates in fungal diversity-litter decomposition relationships. (2005) Ecology Letters, vol. 8 (n 11). pp. 1129-1137. ISSN 1461-023X

Any correspondance concerning this service should be sent to the repository administrator: staff-oatao@,listes-diff.inp-toulouse.fr 


\section{Magnitude and variability of process rates in fungal diversity-litter decomposition relationships}

\author{
Christian K. Dang, ${ }^{1,2 *}$ Eric \\ Chauvet $^{1}$ and Mark 0. Gessner ${ }^{2}$ \\ ${ }^{1}$ Laboratoire Dynamique de la \\ Biodiversité, UMR 5172 CNRS- \\ UPS, 29, rue Jeanne Marvig, \\ 31055 Toulouse Cedex, France \\ ${ }^{2}$ Department of Limnology, \\ Eawag/ETH, 6047 \\ Kastanienbaum, Switzerland \\ *Correspondence: E-mail: \\ christian.dang@eawag.ch
}

\begin{abstract}
There is compelling evidence that losses in plant diversity can alter ecosystem functioning, particularly by reducing primary production. However, impacts of biodiversity loss on decomposition, the complementary process in the carbon cycle, are highly uncertain. By manipulating fungal decomposer diversity in stream microcosm experiments we found that rates of litter decomposition and associated fungal spore production are unaffected by changes in decomposer diversity under benign and harsher environmental conditions. This result calls for caution when generalizing outcomes of biodiversity experiments across systems. In contrast to their magnitude, the variability of process rates among communities increased when species numbers were reduced. This was most likely caused by a portfolio effect (i.e. statistical averaging), with the uneven species distribution typical of natural communities tending to weaken that effect. Curbing species extinctions to maintain ecosystem functioning thus can be important even in situations where process rates are unaffected.
\end{abstract}

\section{Keywords}

Aquatic hyphomycetes, biodiversity, decomposition, ecosystem functioning, fungi, leaf litter, stability.
The current rapid rates of species extinctions worldwide have raised concerns about the consequences of impoverished communities on ecosystem functioning and services (Kinzig et al. 2001; Loreau et al. 2002a; Hooper et al. 2005). This in turn has prompted much experimental research and theoretical advances towards understanding biodiversity effects on ecosystem processes (Fridley 2001; Loreau et al. 2001; Naeem 2002; Covich et al. 2004; Hooper et al. 2005). The most comprehensive experiments have centred on vascular plant production (i.e. primary productivity) in grasslands; they have provided convincing evidence that biodiversity losses can indeed curtail ecosystem functioning (e.g. Tilman et al. 2001; van Ruijven \& Berendse 2003; Hooper et al. 2005; Spehn et al. 2005).

Changes in biodiversity can also affect plant litter decomposition (Covich et al. 2004; Gartner \& Cardon 2004; Hättenschwiler \& Gasser 2005). This process is complementary to, and equally important as, primary production in both terrestrial and many aquatic ecosystems. It involves a range of microbial decomposers and detritivorous consumers differing in functional traits (e.g.
Ruesink \& Srivastava 2001; Hieber \& Gessner 2002; Heemsbergen et al. 2004), and the diversity of plant litter (Gartner \& Cardon 2004) and species interactions in intricate food webs (Wardle et al. 2004) add further to the complexity of decomposer systems. This suggests that there is considerable potential for biodiversity to influence plant litter decomposition. Accordingly, effects on decomposition have been observed in response to diversity manipulations of plant litter (Swan \& Palmer 2004; Hättenschwiler \& Gasser 2005), detritivores (Jonsson \& Malmqvist 2000; Heemsbergen et al. 2004) and microbes (Griffiths et al. 2001; Bärlocher \& Corkum 2003; Setälä \& McLean 2004; Duarte et al. 2005; Tiunov \& Scheu 2005), but overall outcomes of these experiments have been equivocal (Covich et al. 2004; Gartner \& Cardon 2004; Spehn et al. 2005).

An important aspect in the assessment of biodiversity effects on ecosystem functioning is that losses in biodiversity may increase variability in process rates, in addition to changing the magnitude of rates (Doak et al. 1998; Cottingham et al. 2001; Loreau et al. 2002b). Indeed, a range of factors has been identified that may reduce 
variability of process rates as diversity decreases. They include both biological and statistical mechanisms (McCann 2000; Cottingham et al. 2001), with theoretical work suggesting that the prominent mechanism is the so-called portfolio effect (or statistical averaging; Doak et al. 1998; Tilman et al. 1998). It refers to the fact that process rates achieved by mixed communities tend to converge as the number of species in the communities rises because the influence of extreme species will be increasingly dampened. Although theoretically evident, this idea has not been challenged by experimental testing.

We used a simple, well-controlled model system to explore whether changes in microbial diversity have implications for both the magnitude and variability of ecosystem process rates. The experimental system, stream microcosms supplied with plant litter and fungal communities of known composition, combines realism with ease of manipulation (Suberkropp 1991). The measured responses included rates of litter decomposition and associated fungal spore production, which constitutes a high-quality food supply for fine-particle consumers (Bärlocher \& Brendelberger 2005). Specifically, we tested (1) whether decomposition and spore production rates are altered as fungal diversity decreases; (2) whether diversity effects depend on the relative decomposability of litter types and/or external nutrient supply; (3) whether biodiversity effects could be explained by species interactions (e.g. facilitation, resource complementarity, antagonism); and (4) whether variability in process rates across communities deviates from theoretically expected patterns.

\section{METHODS}

Experiments were carried out in microcosms designed to mimic leaf decomposition by fungi in streams (Suberkropp 1991). Microcosms consisted of $50 \mathrm{~mL}$ glass chambers aerated from the bottom by a continuous air flow (80$100 \mathrm{~mL} \mathrm{~min}^{-1}$ ) to create turbulence that keeps leaf pieces in permanent motion. A tap at the bottom allows aseptic drainage of the chambers and recovery of suspended spores without removing leaf pieces. Fresh medium is dispensed through the open tops of the microcosms which are otherwise covered with a glass lid. Fourteen species of common aquatic hyphomycetes were isolated from single spores collected in foam from two neighbouring forest streams in southern France (Table 1). The streams had similar characteristics and fungal species composition, so any combination of the 14 species can be viewed as an excerpt of a natural community. Spores for inoculating microcosms were produced by submerging pieces of 7-10day old axenic colonies in a mineral salt solution containing per litre $100 \mathrm{mg} \mathrm{CaCl} \cdot 2 \mathrm{H}_{2} \mathrm{O}, 10 \mathrm{mg} \mathrm{MgSO}_{4} \cdot 7 \mathrm{H}_{2} \mathrm{O}$, $0.5 \mathrm{~g}$ morpholino propane sulfonic acid (MOPS), $100 \mathrm{mg} \mathrm{KNO}$ and $5.5 \mathrm{mg} \mathrm{K}_{2} \mathrm{HPO}_{4}$, with aeration and $\mathrm{pH}$ adjusted to 7.0 .

Of the total pool of 14 species, only 12 were used in each of three separate experiments because some species sometimes failed to produce sufficient spores to inoculate microcosms. Nine distinct species combinations at each of four diversity levels (two, four, six and eight species) were randomly drawn from these pools (Table 1); for compar-

\begin{tabular}{llll}
\hline & \multicolumn{3}{l}{ Experimental conditions } \\
\cline { 2 - 4 } Fungal species & Alder high & Alder low & Oak high \\
\hline Alatospora acuminata Ingold & + & $0 / 2$ & $0 / 1$ \\
Anguillospora longissima (Saccardo \& Sidow) Ingold & & + & $1 / 0$ \\
Articulospora tetracladia Ingold & $1 / 0$ & $2 / 1$ & $2 / 1$ \\
Clavariopsis aquatica de Wildeman & $2 / 3$ & $0 / 1$ & \\
Flagellospora curvula Ingold & + & + & $0 / 1$ \\
Goniopila monticola (Dyko) Marvanová \& Descals & + & + & + \\
Heliscus lugdunensis Saccardo \& Thérry & + & $0 / 1$ & + \\
Lemmoniera aquatica de Wildeman & + & $1 / 0$ & $1 / 1$ \\
Lemmoniera terrestris Tubaki & $0 / 3$ & & + \\
Tetrachaetum elegans Ingold & + & + & + \\
Tetracladium marchalianum de Wildeman & $6 / 3$ & $6 / 3$ & $1 / 1$ \\
Tetracladium setigerum (Grove) Ingold & + & & \\
Tricladium chaetocladium Ingold & & + & + \\
Tumularia aquatica Ingold (Descals \& Marvanová) & + & $0 / 1$ & $4 / 4$ \\
\hline
\end{tabular}

Table 1 Compilation of fungal species used in experiments with two types of leaf litter and at two levels of nutrient supply

Numbers before and after the slash indicate how often a particular species dominated the eight- and six-species mixtures, respectively, of a total of nine species combinations in both cases.

The + signs refer to the remaining species present in a given experiment. 
ison, five to 12 species are typically found on a single leaf decomposing in natural streams (Bärlocher 1992). In addition to the mixed communities, all 12 species used in a given experiment were grown in monoculture. Experimental conditions were varied in terms of litter recalcitrance by using alder and oak leaves and, for alder leaves, two levels of nutrient concentrations (either $100 \mathrm{mg} \mathrm{L}^{-1} \mathrm{KNO}_{3}$ and $5.5 \mathrm{mg} \mathrm{L}^{-1} \mathrm{~K}_{2} \mathrm{HPO}_{4}$, or $10 \mathrm{mg} \mathrm{L}^{-1} \mathrm{KNO}_{3}$ and $0.55 \mathrm{mg} \mathrm{L}^{-1} \mathrm{~K}_{2} \mathrm{HPO}_{4}$ ).

One-centimetre diameter leaf discs were cut from freshly fallen leaves of alder [Alnus glutinosa (L.) Gaertn.] and oak (Quercus robur L.) collected in October 2002, stored frozen and later air-dried before weighing. Batches of 20 discs (92-124 mg dry mass weighed to the nearest $0.1 \mathrm{mg}$ ) were introduced into each microcosm and autoclaved. Forty $\mathrm{mL}$ of mineral salt solution was added, the microcosms aerated for $24 \mathrm{~h}$ and then inoculated with 5000 fungal spores (Treton et al. 2004) partitioned equally among all species in a given species mixture. The mineral salt solution was replaced after $24 \mathrm{~h}$ and then every 3 days. Aliquots of the spore suspensions drained from microcosms were preserved with formaldehyde (3\% final concentration) amended with $0.01 \%$ Triton X100. Experiments ran for 28 days with alder at high nutrient level at $15{ }^{\circ} \mathrm{C}$. Duration was extended to 42 days both with alder leaves at low nutrient level and with oak leaves to achieve a similar overall decomposition compared to alder leaves at high nutrient levels. Leaf-discs were collected at the end of experiments, dried, and weighed to the nearest $0.1 \mathrm{mg}$.

Realized fungal community composition was assessed as total spore output. The spore suspensions of each microcosm resulting from multiple changes of the medium were combined and aliquots filtered through membrane filters (5 $\mu \mathrm{m}$ pore size). The trapped spores were stained with $0.1 \%$ Trypan blue in 50\% lactic acid, counted and identified at 160-200x. Spore numbers were converted to spore biomass by using conversion factors established empirically (Chauvet \& Suberkropp 1998) or derived from spore volumes and dry mass densities (Baldy et al. 2002).

Litter decomposition was assessed as percent dry mass loss. Analyses based on arcsine square root transformations and on exponential leaf decay coefficients $(k)$ produced very similar results in statistical analyses. Diversity effects were tested by ANOVA (with species richness, $S$, as the predictive variable) or linear regression (Shannon-Wiener's diversity index, $H$, as the predictive variable).

To detect species interactions within mixed communities, the relation between either $S$ or $H$, and the total spore production of mixtures was analysed by first calculating Relative Yield Totals $(R Y T)$ as $\sum\left(N_{i \text {,mix }} / N_{i \text {,mono }}\right)$, where $N_{i, \text { mix }}$ and $N_{i \text {,mono }}$ are the total spore numbers produced by species $i$ in the mixture and monoculture, respectively (Hector 1998). Because RYTs are relative values, calculations based on spore biomass give identical results. Effects of diversity measures on $R Y T$ were then tested by ANOVA or linear regression, respectively. When no significant effect was detected, the RYT pooled across diversity levels was tested against the null hypothesis that $R Y T=1$, using a one-sample $t$-test (Bärlocher \& Corkum 2003). The latter test was used to detect positive or negative species interactions affecting total spore output in species mixtures.

The relative deviation of observed leaf mass loss in a species mixture from its expected value $\left(D_{T}\right)$ was calculated as $\left(O_{T}-E_{T}\right) / E_{T}$, where $O_{T}$ is the observed and $E_{T}$ the expected mass loss in mixtures (Wardle et al. 1997; Hector et al. 2002). $E_{T}$ was calculated as $\sum\left(B_{i, \text { mix }} / B_{i, \text { mono }} \times L_{i, \text { mono }}\right)$, where $B_{i, \text { mix }}$ and $B_{i, \text { mono }}$ is the spore biomass produced by species $i$ in the mixture and monoculture, respectively, and $L_{i \text { mono }}$ is the leaf mass loss caused by species $i$ in monoculture. The assumption underlying this approach is that spore biomass output of any given species $i$ is proportional to the litter mass loss caused by this species, which is realistic in view of strong correlations between sporulation and decomposition found in both microcosm (Suberkropp 1991) and field studies (e.g. Gessner \& Chauvet 1994; Sridhar \& Bärlocher 2000). Effects of diversity measures on $D_{T}$ were first tested by ANOvA and linear regression, respectively, and when no significant effect was detected, the $D_{T}$ pooled across diversity levels was tested against the null hypothesis that $D_{T}=0$, using a one-sample t-test (Bärlocher \& Corkum 2003).

We used the coefficient of variation $(\mathrm{CV})$ as a measure of variability of process rates among communities with a given diversity level (i.e. one, two, four, six or eight species) and then compared coefficients of variation among diversity levels. This is analogous to considering temporal variability in a scenario were species are successively lost from communities. To test whether variability increased with decreasing diversity, we regressed CVs against species richness ( $S$ ) under the assumption that the relationships followed a power law, $\mathrm{CV}=a \cdot S^{b}$, where $a$ and $b$ are estimated parameters (Doak et al. 1998). The least-square Gauss-Newton procedure in SYSTAT was used for nonlinear curve fitting. When regressions were significant, we also tested against a null model assuming a portfolio effect (Doak et al. 1998; Tilman et al. 1998) and equal abundances of all species in mixed assemblages. To this end, we first calculated expected coefficients of variation $\left(\mathrm{CV}_{\exp , j}\right)$ for mixtures at each diversity level $j$ from the monoculture of each species $i\left(M_{i, \text { mono }}\right)$ as

$\mathrm{CV}_{\exp , j}=\sigma \sum\left(p_{i, j} M_{i, \text { mono }}\right) / \mu \sum\left(p_{i, j} M_{i, \text { mono }}\right) \times 100$,

where $\sigma$ is the standard deviation and $\mu$ the mean, and then compared the observed and expected $\mathrm{CV}$ with a paired 
$t$-test. A significant difference would suggest some mechanism other than the portfolio effect to be involved in any observed increases in variability with decreasing species richness. SYSTAT 10.0 was used for all statistical analyses (SPPS Inc., Chicago, IL, USA). Results were considered significant when $P<0.05$.

\section{RESULTS}

All species were generally successful in establishing and completing their life cycle on leaves in our experiments; only five of the 384 individual fungi inoculated in our 144 microcosms were lost. Communities in higher diversity treatments ( $S=6$ or 8 ) showed typical features of natural communities with one or a few dominants and a majority of less abundant species (Fig. 1). Although a variety of different species dominated the mixed communities (four to seven species in the six and eight-species mixtures), there was an apparent tendency for Tetracladium marchalianum to assume dominance in the experiments with alder and for Tumularia aquatica to dominate communities on oak leaves (Table 1). In addition, dominance patterns varied slightly among experiments, with a shift from high dominance under more favourable conditions to a more even distribution in harsher conditions (Fig. 1).

Both single-species and mixed fungal assemblages caused substantial litter decomposition (Fig. 2). Mass loss of alder leaves proceeded to a similar stage at high and low nutrient levels, ranging from 20 to $43 \%$ (mean $=33 \%$; after correction for initial leaching losses of $27.4 \pm 1.6 \%$; mean $\pm \mathrm{SD}$ ) after 28 days and $20-48 \%$ (mean $=36 \%$; initial leaching of $28.0 \pm 1.1 \%$ ) after 42 days, respectively. Average mass loss of oak leaves was somewhat lower, ranging from 5 to $43 \%$ (mean $=24 \%$; initial leaching of $20.8 \pm 2.2 \%$ ) after 42 days. Leaf mass loss in sterile control microcosms after initial leaching was $<3 \%$ in all experiments.

Litter decomposition did not significantly differ among diversity levels in any of the three experiments $(F \leq 1.32$,
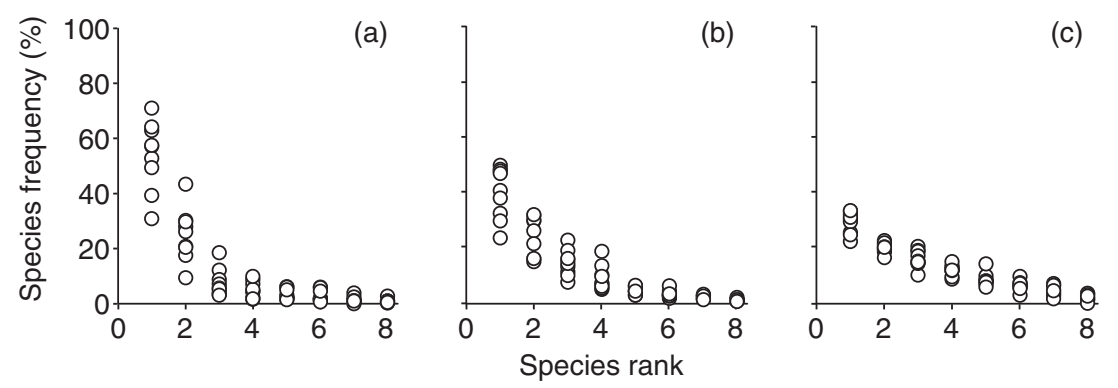

Figure 1 Rank-frequency diagram showing species distributions in the most diverse microcosms (eight species). (a) Alder leaves and high dissolved nutrient supply; (b) alder leaves and low nutrient supply; and (c) oak leaves and high nutrient supply.

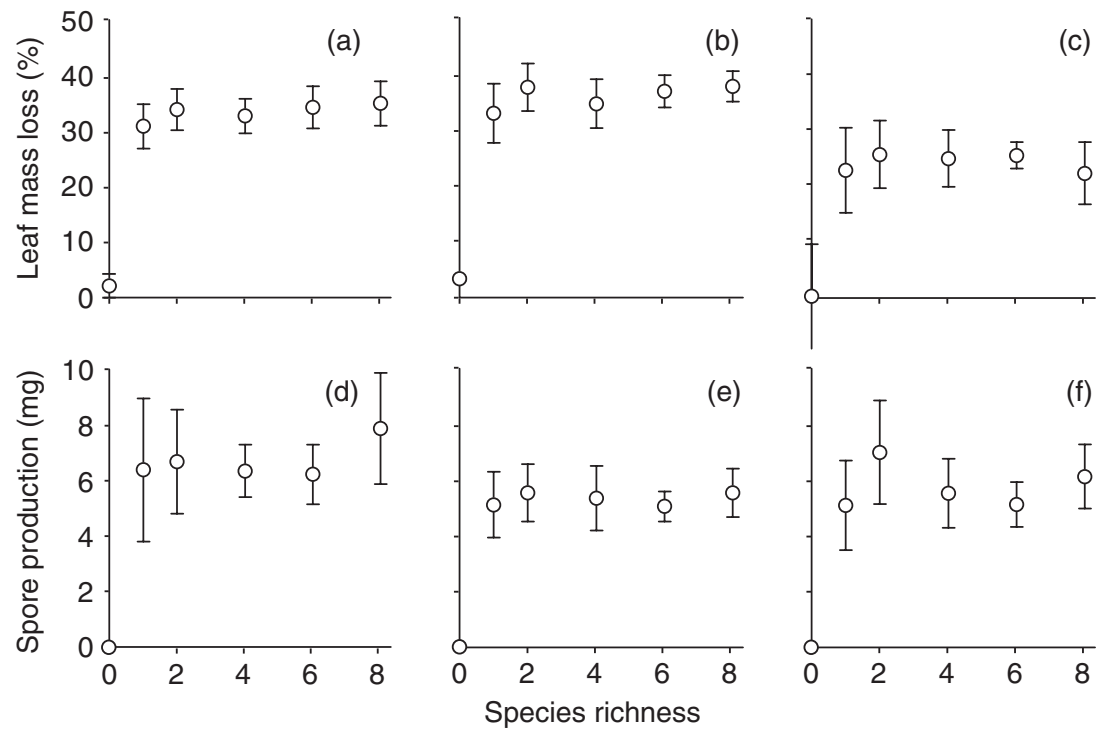

Figure 2 Leaf mass loss $(\mathrm{a}, \mathrm{b}, \mathrm{c})$ and total fungal spore production (d, e, f) as a function of fungal species richness $(S)$ in stream microcosms with alder leaves and either high (a, d) or low (b, e) supplies of dissolved nutrients, or with oak leaves and high nutrient supplies (c, f). 
Figure 3 Relative Yield Totals $(R Y T)$ and Deviation from Expected Values $\left(D_{T}\right)$ as a function of species richness $(S)$ of fungal communities on alder leaves with high (a, d) or low (b, e) nutrient supply or on oak leaves with high nutrient supply (c, f).
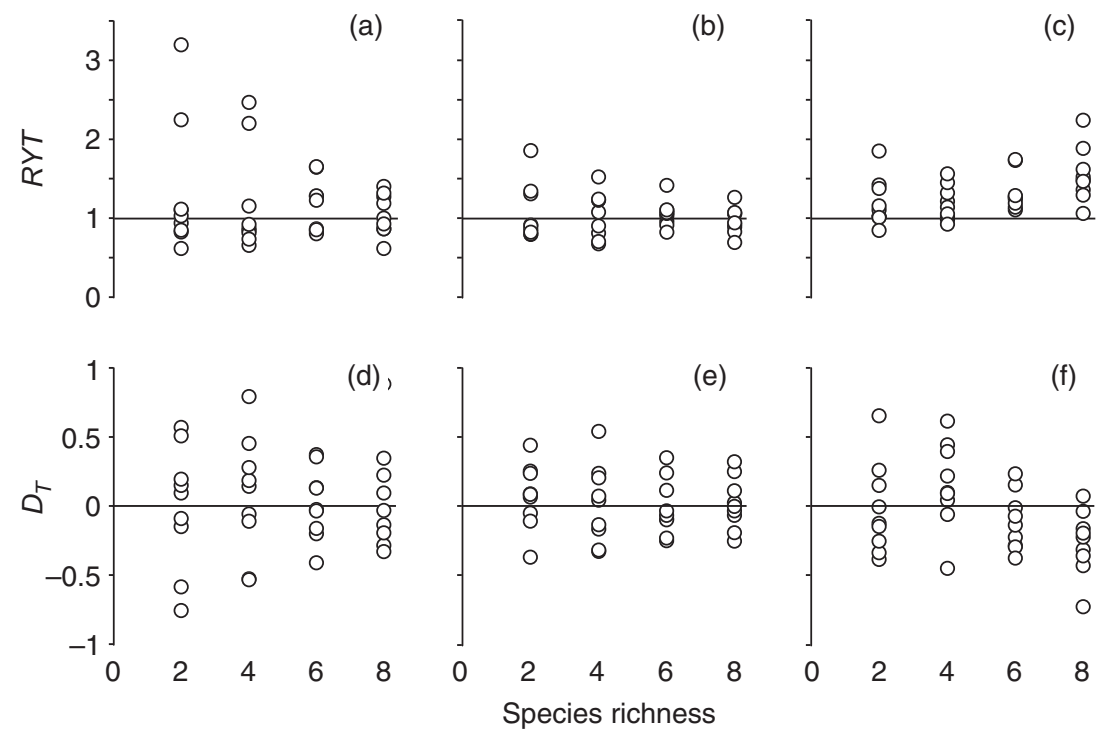

$P \geq 0.28$ ), nor was total spore biomass production significantly affected $(F \leq 1.60, P \geq 0.19)$ (Fig. 2). Nearly identical results are obtained when $H$ is substituted for species richness $(S)$.

Fungal diversity on alder leaves also failed to affect $R Y T \mathrm{~s}$ of spore biomass production, regardless of whether $S$ (Fig. 3) or $H\left(R^{2} \leq 0.04, P \geq 0.22\right)$ was used as the diversity measure. $R Y T \mathrm{~s}$ in the two experiments with alder were close to 1 (Fig. 3a,b; $t \leq 1.68, P \geq 0.10$ ), indicating that net positive $(R Y T>1)$ or negative $(R Y T<1)$ interactions among species were unlikely. However, a significant positive effect was observed in the experiment with oak leaves (Fig. 3c; $F=3.2, P<0.05$ for $S ; R^{2}=0.15, P=0.02$ for $H)$, suggesting a tendency in mixtures towards denser sporulation, and thus greater activity (e.g. Suberkropp 1991; Hieber \& Gessner 2002; Bärlocher \& Corkum 2003; Treton et al. 2004), than expected based on results from monocultures.

Similar to absolute leaf mass loss, no significant differences among diversity levels were detected for $D_{T}$ (i.e. the relative deviation of observed and expected mass loss) in experiments with alder leaves (Fig. 3d,e; $F \leq 0.19, P \geq 0.90$ for $S ; R^{2} \leq 0.04, P \geq 0.26$ for $H$ ), nor $\operatorname{did} D_{T}$ values significantly differ from zero when data were pooled across diversity levels $(t \leq 1.10, P \geq 0.28)$. In the experiment with oak leaves, a significant effect on $D_{T}$ was detected (Fig. 3f), but post-hoc Tukey's test revealed that it was due to a single significant difference between diversity levels 4 and 8 $(P=0.02)$.

CVs of both leaf mass loss and sporulation rate (i.e. process rate variability) decreased consistently with increasing diversity (Fig. 4). Under the assumptions of a portfolio effect and equally abundant species, the observed decrease was never steeper than expected (dotted lines in Fig. 4; see
Doak et al. 1998). When the realized differences in species abundance are considered, this pattern did not notably change for the CVs of decomposition rate, but for sporulation the decreasing tendencies of $\mathrm{CVs}$ became weaker (dashed lines in Fig. 4). Thus, strength of the portfolio effect was sufficient to fully account for the observed decrease in process rate variability, with realized uneven species distributions partly offsetting this stabilizing statistical effect in some cases.

\section{DISCUSSION}

\section{Effects on the magnitude of process rates}

Experiments manipulating vascular plant diversity have revealed clear diversity effects on primary productivity with increasing species richness of both plants and mycorrhizae (van der Heijden et al. 1998; Tilman et al. 2001; van Ruijven \& Berendse 2003, 2005; Hooper et al. 2005; Spehn et al. 2005). In contrast, diversity of fungal decomposers consistently failed to affect decomposition and spore production rates irrespective of the diversity measure used. This lends support to the idea that litter decomposition and associated processes are considerably more resistant to losses in fungal decomposer diversity than primary production in response to reduced species richness of plants or mycorrhizal fungi. Caution is needed, therefore, when extrapolating results from biodiversity-ecosystem functioning experiments across vastly different types of communities and ecosystem processes.

Degrees of competitive and facilitative interactions among species are expected to change along gradients of environmental harshness (Setälä \& McLean 2004). Accordingly, we hypothesized that the strength of diversity effects 

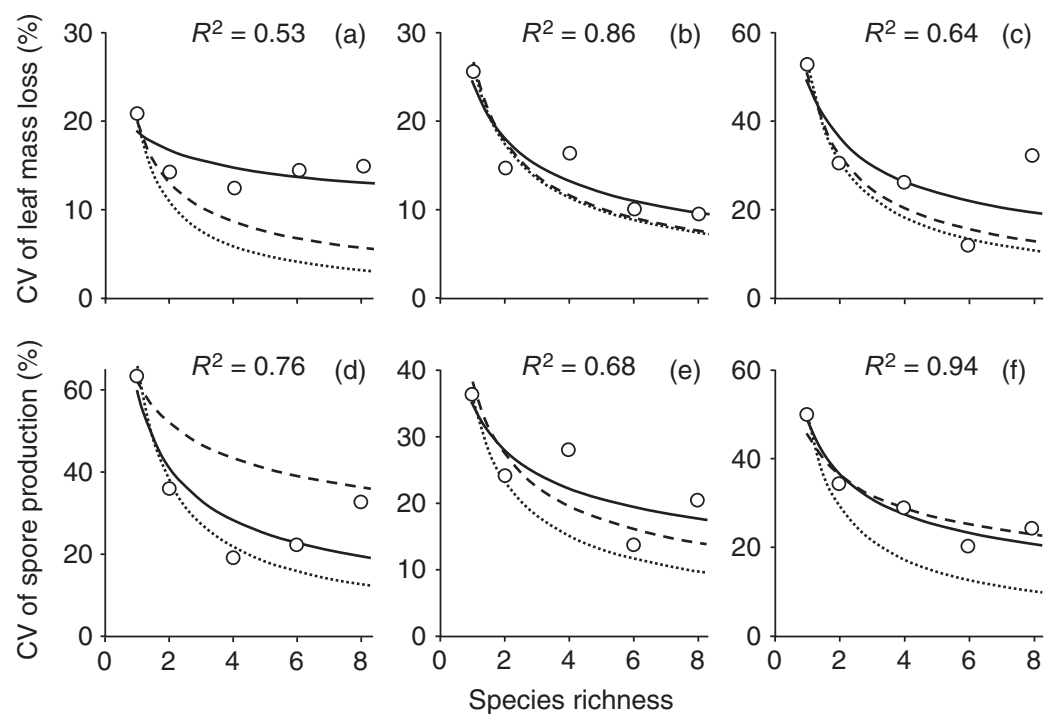

Figure 4 Power-law relationship between species richness and coefficients of variation (CV) of leaf mass loss (a, b, c) and spore production (d, e, f). Experiments were carried out with alder leaves and high (a, d) or low (b, e) nutrient supply, or with oak leaves and high nutrient supply (c, f). $R^{2}$ refers to the adjusted $R^{2}$ values of nonlinear curve fitting for the empirically observed relationships (solid black lines). The dotted lines represent the portfolio effect assuming an even species distribution, while the dashed lines represent the portfolio effect with realized communities. would depend on litter recalcitrance and external nutrient supply, which both are key determinants of leaf decomposition and fungal activity (Gessner \& Chauvet 1994; Gulis \& Suberkropp 2003). However, although the structure of fungal communities changed among experiments (Table 1, Fig. 1), neither litter quality nor nutrient supply affected responses of process rates to changing fungal diversity (Fig. 2). This unresponsiveness is consistent with results from experiments with pelagic microbes in which light (here equivalent to carbon availability) and nutrient levels were manipulated (Naeem \& Li 1997). Our conclusion of greater resistance to fungal species losses of litter decomposition rate in our experiments thus appears to hold under both benign and harsher environmental conditions.

Superficially, our results are at variance with a recent report suggesting positive fungal diversity effects on decomposition (Bärlocher \& Corkum 2003). However, our assessment is based on realized fungal communities rather than on species proportions in inoculum mixtures. This difference is critically important (Huston et al. 2000). If genuine communities with a few dominant and a majority of rare species establish on leaves, as was the case in our experiments (Fig. 1), then large consequences will ensue for $D_{T}$ values. It is those on which Bärlocher \& Corkum's (2003) conclusion of positive diversity effects is based, indicating that a spurious effect could have resulted from an oversimplified description of fungal communities. The microcosms we used allowed us to overcome this problem by ascertaining realized community structure.

In addition to a statistical mechanism known as sampling effect (i.e. the higher probability at higher diversity levels to include more efficient species that subsequently dominate communities; Aarsen 1997; Huston 1997), niche partitioning and facilitation, two biological mechanisms, may underlie biodiversity effects on ecosystem processes (Loreau 2000; Hooper et al. 2005). Spatial niche partitioning can occur when fungi occupy distinct areas in decomposing leaves, such as veins vs. parenchymatous tissue or spongy vs. palisade parenchyma, and segregation of species in time (i.e. temporal niche partitioning) can also occur, as suggested by predictable successional changes in fungal communities as leaves decompose (Bärlocher 1992; Gessner et al. 1993). Facilitation, the second biological mechanism underlying positive biodiversity effects, can be mutual or unilateral. It would result when fungal metabolic capacities or activities complement each other, or when some species scavenge degradation products released through the activity of others, thus suppressing enzyme repression in the enzyme-producing fungus. There is evidence from experiments with two species of leaf-degrading microfungi (Treton et al. 2004) that such interactive effects may indeed be important, and can have large consequences for litter decomposition.

Why then did we fail to detect effects in our multispecies experiments? First, although both fungi used in the previous study (Treton et al. 2004) were included in our species pool, neither one assumed dominance in our assembled communities, which made it difficult to detect interactions between them (Loreau et al. 2001). Therefore, the striking effects reported by Treton et al. (2004) may have been because of specific species traits, and their unique combination, rather than to a general diversity effect. Phrased differently, fungal species identity may have mattered more than diversity per se, an outcome also noted in experiments with detritivorous invertebrates (Dangles \& Malmqvist 2004; Heemsbergen et al. 2004). Alternative hypotheses accounting for the lack of biodiversity effects in our experiments include that niche partitioning and facilitation effects were weak or absent, or 
that they were counteracted by antagonistic species interactions (Gulis \& Stephanovich 1999) resulting in reduced growth and resource use.

We also found no indication of a sampling effect (Aarsen 1997; Huston 1997), although large differences in leaf decomposition and sporulation occurred between the most and least effective species in monoculture. However, single species did not prominently stand out in terms of their capacity to decompose leaves or produce spores, but rather displayed a continuum in their leaf-degrading capabilities. Furthermore, the influence of single species on average process rates was dampened by our experimental design that ensured species mixtures never contained more than twothirds of the total species pool (i.e. eight of 12 species). Thus, the observed absence of a manifest sampling effect was not unexpected.

\section{Effects on process rate variability}

Although fungal diversity did not affect average process rates (i.e. the magnitude of processes), there was a remarkably consistent tendency towards greater variability across fungal communities at lower diversity levels. Other studies have reported concordant results when considering temporal variability of communities (McGrady-Steed et al. 1997; Cottingham et al. 2001). This and the good correspondence across our three experiments highlight the importance of biodiversity for ecosystem functioning even when direct diversity effects on the magnitude of processes are undetectable.

Relationships between diversity and variability of process rates may be influenced by a range of factors (McCann 2000; Cottingham et al. 2001). The approach we have taken to test against a null model assuming a portfolio effect (Doak et al. 1998; Tilman et al. 1998) showed that this mechanism could fully account for the decreased variability in process rates with increasing diversity: observed decreases in CVs were never stronger than expected under the assumption of a portfolio effect, as indicated by the invariably steeper regression curves describing the portfolio effect with evenly distributed species (dotted lines in Fig. 4). Although unrealistic, such an even distribution of species is instructive because it defines the maximum possible reduction in process rate variability that could be caused by the portfolio effect. Accordingly, the highly uneven realized distribution of species in our experimental communities consistently weakened the portfolio effect (dashed lines in Fig. 4), as has been shown theoretically (Doak et al. 1998). In two of our three experiments, this resulted in a very good match between the regression curves of observed and expected CVs, suggesting that the combined portfolio and evenness effects may well account for those empirical observations.
In conclusion, fungal diversity, whether assessed as species richness or Shannon-Wiener diversity, did not affect the magnitude of leaf decomposition and fungal sporulation. Process variability, in contrast, was consistently affected by fungal diversity. The underlying mechanism was likely a portfolio effect, partly offset in the case of sporulation by the uneven distribution of species in realized communities. An important implication is that ecosystem performance becomes more reliable (Naeem \& Li 1997), or predictable (McGrady-Steed et al. 1997), as species abundances in communities undergo temporal fluctuations, whether these occur as a result of natural population dynamics or in response to species shifts caused by anthropogenic stressors such as pollutants or drivers of global environmental change. Thus, even when diversity may not exert strong effects on the magnitude of ecosystem processes, as shown here, consequences on properties such as process rate variability call for conserving biodiversity on the ground of protecting ecosystem functioning.

\section{ACKNOWLEDGEMENTS}

We thank S. Hättenschwiler, B. Malmqvist, members of the Journal Club at the Eawag Kastanienbaum, and three anonymous reviewers for constructive comments on the manuscript. This research was supported through the RivFunction project funded by the EU Commission (contract no. EVK1-CT-2001-00088) and the Swiss Federal Ministry of Education and Science (BBW no. 01.0087). Additional support was received by C.D. through an ATUPS grant from the University Paul Sabatier in Toulouse, France.

\section{REFERENCES}

Aarsen, L.W. (1997). High productivity in grassland ecosystems: effected by species diversity or productive species? Oikos, 80, 183-184.

Baldy, V., Chauvet, E., Charcosset, J.-Y. \& Gessner, M.O. (2002). Microbial dynamics associated with leaves decomposing in the mainstem and floodplain pond of a large river. Aquat. Microb. Ecol., 28, 25-36.

Bärlocher, F. (1992). Community organization. In: The Ecology of Aquatic Hyphomycetes (ed. Bärlocher, F.). Springer-Verlag, New York, pp. 38-76.

Bärlocher, F. \& Brendelberger, H. (2005). Clearance of aquatic hyphomycete spores by a benthic suspension feeder. Limnol. Oceanogr., 49, 2292-2296.

Bärlocher, F. \& Corkum, M. (2003). Nutrient enrichment overwhelms diversity effects in leaf decomposition by stream fungi. Oikos, 101, 247-252.

Chauvet, E. \& Suberkropp, K. (1998). Temperature and sporulation of aquatic hyphomycetes. Appl. Environ. Microbiol., 64, 15221525. 
Cottingham, K.L., Brown, B.L. \& Lennon, J.T. (2001). Biodiversity may regulate the temporal variability of ecological systems. Ecol. Lett., 4, 72-85.

Covich, A.P., Austen, M.C., Bärlocher, F., Chauvet, E., Cardinale, B.J., Biles, C.L. et al. (2004). The role of biodiversity in the functioning of freshwater and marine benthic ecosystems. BioScience, 54, 767-775.

Dangles, O. \& Malmqvist, B. (2004). Species richness-decomposition relationships depend on species dominance. Ecol. Lett., 7, 395-402.

Doak, D.F., Bigger, D., Harding, E.K., Marvier, M.A., O’Malley, R.E. \& Thomson, D. (1998). The statistical inevitability of stability-diversity relationships in community ecology. Am. Nat., 151, 264-276.

Duarte, S., Pascoal, C., Cássio, F. \& Bärlocher, F. (2005). Aquatic hyphomycete diversity and identity affect leaf litter decomposition in microcosms. Oecologia, in press.

Fridley, J.D. (2001). The influence of species diversity on ecosystem productivity: how, where, and why? Oikos, 93, 514-526.

Gartner, T.B. \& Cardon, Z.G. (2004). Decomposition dynamics in mixed-species leaf litter. Oikos, 104, 230-246.

Gessner, M.O. \& Chauvet, E. (1994). Importance of stream microfungi in controlling breakdown rates of leaf litter. Ecology, 75, 1807-1817.

Gessner, M.O., Thomas, M., Jean-Louis, A.-M. \& Chauvet, E. (1993). Stable successional patterns of aquatic hyphomycetes on leaves decaying in a summer cool stream. Mycol. Res., 97, 163-172.

Griffiths, B.S., Ritz, K., Wheatley, R., Kuan, H.L., Boag, B., Christensen, S. et al. (2001). An examination of the biodiversityecosystem function relationship in arable soil microbial communities. Soil Biol. Biochem., 33, 1713-1722.

Gulis, V.I. \& Stephanovich, A.I. (1999). Antibiotic effects of some aquatic hyphomycetes. Mycol. Res., 103, 111-115.

Gulis, V.I. \& Suberkropp, K. (2003). Leaf litter decomposition and microbial activity in nutrient-enriched and unaltered reaches of a headwater stream. Freshwat. Biol., 48, 123-134.

Hättenschwiler, S. \& Gasser, P. (2005). Soil animals alter plant litter diversity effects on decomposition. Proc. Nat. Acad. Sci. U.S.A., 102, 1519-1524.

Hector, A. (1998). The effect of diversity on productivity: detecting the role of species complementarity. Oikos, 82, 597-599.

Hector, A., Bazeley-White, E., Loreau, M., Otway, S. \& Schmid, B. (2002). Overyielding in grassland communities: detecting the sampling effect hypothesis with replicated biodiversity experiments. Ecol. Lett., 5, 502-511.

Heemsbergen, D.A., Berg, M.P., Loreau, M., van Hal, J.R., Faber, J.H. \& Verhoef, H.A. (2004). Biodiversity effects on soil processes explained by interspecific functional dissimilarity. Science, 306, 1019-1020.

van der Heijden, M.G.A., Klironomos, J.N., Ursic, M., Moutoglis, P., Streitwolf-Engel, R., Boller, T. et al. (1998). Mycorrhizal fungal diversity determines plant biodiversity, ecosystem variability and productivity. Nature, 396, 69-72.

Hieber, M. \& Gessner, M.O. (2002). Contribution of stream detritivores, fungi, and bacteria to leaf breakdown based on biomass estimates. Ecology, 83, 1026-1038.

Hooper, D.U., Chapin, F.S. III, Ewel, J.J., Hector, A., Inchausti, P., Lavorel, S. et al. (2005). Effects of biodiversity on ecosystem functioning: a consensus of current knowledge. Ecol. Monogr., 75, $3-35$.
Huston, M.A. (1997). Hidden treatments in ecological experiments: Re-evaluating the ecosystem function of biodiversity. Oecologia, 110, 449-460.

Huston, M.A., Aarsen, L.W., Austin, M.P., Cade, B.S., Fridley, J.D., Garnier, E. et al. (2000). No consistent effect of plant diversity on productivity. Science, 289, 1255a.

Jonsson, M. \& Malmqvist, B. (2000). Ecosystem process rate increases with animal species richness: Evidence from leaf-eating, aquatic insects. Oikos, 89, 519-523.

Kinzig, A.P., Tilman, D.G. \& Pacala, S. (2001). The Functional Consequences of Biodiversity: Empirical Progress and Theoretical Extensions. Princeton University Press, Princeton, NY.

Loreau, M. (2000). Biodiversity and ecosystem functioning: recent theoretical advances. Oikos, 91, 3-17.

Loreau, M., Downing, A., Emmerson, M., Gonzalez, A., Hughes, J., Inchausti, P. et al. (2002b). A new look at the relationship between diversity and stability. In: Biodiversity and Ecosystem Functioning (eds Loreau, M., Naeem, S. \& Inchausti, P.). Oxford University Press, Oxford, pp. 79-91.

Loreau, M., Naeem, S. \& Inchausti, P. (2002a). Biodiversity and Ecosystem Functioning: Synthesis and Perspective. Oxford University Press, Oxford.

Loreau, M., Naeem, S., Inchausti, P., Bengtsson, J., Grime, P.J., Hector, A. et al. (2001). Biodiversity and ecosystem functioning: current knowledge and future challenges. Science, 294, 804-808.

McCann, K.S. (2000). The diversity-stability debate. Nature, 405, 228-233.

McGrady-Steed, J., Harris, P. \& Morin, P.J. (1997). Biodiversity regulates ecosystem predictability. Nature, 390, 162-165.

Naeem, S. (2002). Ecosystem consequences of biodiversity loss: the evolution of a paradigm. Ecology, 83, 1537-1552.

Naeem, S. \& Li, S. (1997). Biodiversity enhances ecosystem reliability. Nature, 390, 507-509.

Ruesink, J.L. \& Srivastava, D.S. (2001). Numerical and per capita responses to species loss: mechanisms maintaining ecosystem function in a community of stream insect detritivores. Oikos, 93, 221-234.

Setälä, H. \& McLean, A. (2004). Decomposition rate of organic substrates in relation to the species diversity of soil saprophytic fungi. Oecologia, 139, 98-107.

Spehn, E.M., Hector, A., Joshi, J., Scherer-Lorenzen, M., Schmid, B., Bazeley-White, E. et al. (2005). Ecosystem effects of biodiversity manipulations in European grasslands. Ecol. Monogr., 75, 37-63.

Sridhar, K.R. \& Bärlocher, F. (2000). Initial colonization, nutrient supply, and fungal activity on leaves decaying in streams. Appl. Environ. Microbiol., 66, 1114-1119.

Suberkropp, K. (1991). Relationships between growth and sporulation of aquatic hyphomycetes on decomposing leaf litter. Mycol. Res., 95, 843-850.

Swan, C.M. \& Palmer, M.A. (2004). Leaf diversity alters litter breakdown in a Piedmont stream. J. N. Am. Benthol. Soc., 23, 15-28.

Tilman, D., Lehman, C.L. \& Bristow, C.E. (1998). Diversitystability relationships: statistical inevitability or ecological consequence? Am. Nat., 151, 277-282.

Tilman, D., Reich, P.B., Knops, J., Wedin, D., Mielke, T. \& Lehman, C.L. (2001). Diversity and productivity in a long-term grassland experiment. Science, 294, 843-845.

Tiunov, A.V. \& Scheu, S. (2005). Facilitative interactions rather than resource partitioning drive diversity-functioning relationships in laboratory fungal communities. Ecol. Lett., 8, 618-625. 
Treton, C., Chauvet, E. \& Charcosset, J.-Y. (2004). Competitive interaction between two aquatic hyphomycete species and increase in leaf litter breakdown. Microb. Ecol., 48, 439-446.

van Ruijven, J. \& Berendse, F. (2003). Positive effects of plant species diversity on productivity in the absence of legumes. Ecol. Lett., 6, 170-175.

van Ruijven, J. \& Berendse, F. (2005). Diversity-productivity relationships: Initial effects, long-term patterns and underlying mechanisms. Proc. Nat. Acad. Sci. U.S.A., 102, 695-700.

Wardle, D.A., Bonner, K.I. \& Nicholson, K.S. (1997). Biodiversity and plant litter: experimental evidence which does not support the view that enhanced species richness improves ecosystem function. Oikos, 79, 247-258.

Wardle, D.A., Bardgett, R.D., Klironomos, J.N., Setälä, H., van der Putten, W.H. \& Wall, D.H. (2004). Ecological linkages between aboveground and belowground biota. Science, 304, 1629-1633.

Editor, David Wardle

Manuscript received 3 May 2005

First decision made 7 June 2005

Manuscript accepted 30 June 2005 